\title{
Food proteins as a source of bioactive peptides with diverse functions
}

\author{
Kay J. Rutherfurd-Markwick* \\ Institute of Food, Nutrition and Human Health, Massey University, Albany, New Zealand
}

(Submitted 27 July 2011 - Final revision received 25 September 2011 - Accepted 14 November 2011)

\begin{abstract}
In addition to supplying essential nutrients, some food proteins can confer additional health benefits beyond nutrition. The presence of bioactive proteins and peptides in different foods is a factor not currently taken into consideration when assessing the dietary quality of food proteins. The range of described physiological benefits attributed to bioactive proteins and peptides is diverse. Multiple factors can potentially impact on the ability of a bioactive peptide or protein to elicit an effect. Although some food proteins act directly in their intact form to elicit their effects, generally it is peptides derived from digestion, hydrolysis or fermentation that are of most interest. The levels of bioactive peptides generated must be sufficient to elicit a response, but should not be so high as to be unsafe, thus causing negative effects. In addition, some peptides cause systemic effects and therefore must be absorbed, again in sufficient amounts to elicit their action. Many studies to date have been carried out in vitro; therefore it is important that further trials are conducted in vivo to assess efficacy, dose response and safety of the peptides, particularly if health related claims are to be made. Therefore, methods must be developed and standardised that enable the measurement of health benefits and also the level of bioactive peptides which are absorbed into the bloodstream. Once standardised, such methods may provide a new perspective and an additional mechanism for analysing protein quality which is currently not encompassed by the use of the protein digestibility-corrected amino acid score (PDCAAS).
\end{abstract}

\section{Key words: Bioactive peptides: physiological activity: health benefits}

\section{Introduction}

The past two decades has seen considerable interest in the area of functional foods and bioactive peptides from both scientists and the potential consumer. It is now recognised that some food proteins and food-derived peptides are able to elicit beneficial physiological effects and therefore have the potential to influence health and may help reduce the risk of chronic disease. Hence there is considerable commercial interest in the development of products with potential health benefits, and consequently there are already a number of such products commercially available in different countries around the world such as Japan, USA and Europe ${ }^{(1)}$.

Although much of the work to date has focused on milk, cheese and other dairy products as sources of bioactive proteins and peptides, interest in other sources of food-derived bioactive peptides is continuing to grow and gain momentum. Various fish species such as sardines, tuna, bonito and salmon have been found to be viable sources of bioactive peptides as have other animal products such as blood, eggs and gelatine. Plants are also potential sources, with studies reporting bioactive peptides derived from pulses, wheat, rice, soya, pumpkin and even mushrooms. Clearly the reported sources of bioactive peptides are numerous as are the range of biological effects attributed to their consumption.

Much less prevalent is detailed information from animal and human studies demonstrating the efficacy and safety of bioactive peptides. Although many of the products are expected to be safe because they have been consumed for centuries and therefore have GRAS (generally recognised as safe) status there are a number of issues which must also be considered, such as the potential for allergenicity or intolerance. It is important that the efficacy of the peptides is determined so that scientifically substantiated claims can be made along with the upper safe limits of products. A significant amount of information is still required to demonstrate that the relevant bioactive peptides are in fact produced and absorbed in sufficient amounts to elicit a beneficial response. This raises another potential issue, if bioactive peptides are to be generated within a food product prior to consumption, for example due to fermentation, it must be shown that the peptides survive the digestive processes and are absorbed in quantities sufficient to cause a physiological effect. Likewise, if the peptide is expected to be generated during digestion, it must be

Abbreviations: ACE, angiotensin-I converting enzyme; CPP, casein phosphopeptides; EGF, epidermal growth factor; FOSHU, food of specific health use; HDL, high-density lipoprotein cholesterol; IBD, inflammatory bowel disease; LDL, low-density lipoprotein; LDL-R, LDL receptor; MBP, milk basic protein; MS, mass spectrometry; PDCAAS, protein digestibility-corrected amino acid score; TGF- $\beta$, transforming growth factor- $\beta$.

*Corresponding author: K. J. Rutherfurd-Markwick, fax +649443 9640, email K.J.Rutherfurd@massey.ac.nz 
shown to be produced and to be absorbed in adequate quantities to elicit an effect. Independent of the method of production of the bioactive peptide the quantity of product required to be consumed must also be realistic. For the safety and confidence of the consumer it is important that the methods used to measure these factors are well documented and preferably standardized.

The present contribution aims to summarise evidence concerning the generation, absorption and health benefits of bioactive proteins and peptides. In addition, the question of whether it is feasible to incorporate measures of health optimisation as an adjunct to classical protein quality description is discussed.

\section{Intact bioactive proteins and peptides with direct effects on the intestine}

Milk is a fluid specifically designed to meet the nutritional and developmental needs of the new-born and undoubtedly has a role beyond nutrition, acting in the infant luminally in the gut at the mucosal surface and after absorption acting systemically to affect gut maturation ${ }^{(2,3)}$. A number of intact proteins, particularly those from milk and those occurring at higher concentrations in colostrum such as immunoglobulins, lactoferrin and growth factors have been shown to directly exert their in vivo effects by acting directly in the intestine ${ }^{(4)}$. In fact it has been reported that intestinal epithelial cells show receptor-mediated binding of lactoferrin ${ }^{(5)}$ and exogenous opioid peptides appear to target the intestinal brush border membrane ${ }^{(6)}$.

At least some of the major bioactive milk proteins such as lactoferrin and immunoglobulins have been shown to be at least partially resistant to digestive enzymes ${ }^{(7-9)}$ making direct effects feasible. While some of these proteins are also precursors for bioactive peptides it is their biological function in their intact form that will be discussed in this section.

The industrial production of lactoferrin which is estimated at over 70 tons annually ${ }^{(10)}$ is a reflection of the commercial interest in this product, largely due to its bioactive properties. Lactoferrin is a naturally occurring iron-binding glycoprotein found in milk, and is widely considered to be an important anti-microbial component for protecting the host against microbial infections ${ }^{(11)}$. However, the prophylactic effects of lactoferrin against septicaemia, which have been demonstrated in vivo are due to more than antimicrobial effects. Lactoferrin has been shown to modulate inflammatory responses by preventing cytokine release from monocytes and also by regulating the proliferation, differentiation and activation of immune cells ${ }^{(12,13)}$.

Lactoperoxidase, the most abundant enzyme in milk has an antimicrobial role and has synergistic effects with immunoglubulins and lactoferrin ${ }^{(10)}$. Epidermal growth factor (EGF) and transforming growth factor- $\beta$ (TGF- $\beta$ ) are both present in bovine colostrum and studies in human infants, suckling rats, lambs and pigs suggest that EGF at least can survive the gastrointestinal tract in neonatal animals ${ }^{(14-17)}$. EGF exhibits multiple effects including exerting a trophic effect on epithelia, leading to acceleration of cell maturation and stimulation of cell proliferation $^{(18)}$. TGF- $\beta$ has been implicated in epithelial cell growth and differentiation and aids in the repair of injured tissue ${ }^{(19)}$. Diets containing TGF- $\beta$ have been shown to have favourable effects in the treatment of various forms of inflammatory bowel disease including: inducing remission and promoting mucosal healing ${ }^{(19-21)}$, reducing intestinal inflammation ${ }^{(20,22)}$, reducing leukocytes, acute phase reactants ${ }^{(23)}$ and expression of interferon- $\gamma^{(20,21)}$. The importance of TGF- $\beta$ in preventing the development of inflammatory bowel disease (IBD) in animal models has been demonstrated in studies which show that both systemic administration and induction of TGF- $\beta$ have protective effects against induced colitis, and administration of anti-TGF- $\beta$ antibodies appears to oblate this effect ${ }^{(24,25)}$. Results such as these clearly suggest there may be a possible role for bioactive peptides in enteral diets used as therapy for IBD.

Since the intestinal concentration of some dietary peptides is high, it is possible that even though their affinity for cellular receptors is relatively low a physiologically significant effect may still occur, particularly since several peptides may act synergistically $^{(3,26,27)}$. Moughan et al. $^{(28)}$ have reported that some food-derived peptides are able to stimulate the secretion of protein in the gut lumen while others either inhibit the reabsorption of amino acids or affect both activities. A large number of reports (reviewed in Moughan et al. ${ }^{(28)}$ ) describe the effects of food-derived bioactive peptides on gut function by regulating the gastric emptying rate and potentially satiety, affecting tissue growth and increasing the secretory and absorptive capacity of the gut. Many of the peptides identified with these effects are opioid agonists and antagonists which will be discussed in a later section.

\section{Release of bioactive peptides}

Although some food proteins are able to elicit their effects by acting directly in their intact form, generally it is peptides (usually between 3 to 20 amino acids in length) derived from the parent protein that are of most interest. There are three main mechanisms by which bioactive peptides can be released; the first two being the result of normal digestive processes: 1) degradation via digestive enzymes 2) digestion via microbial enzymes primarily in the large intestine or 3) in vitro hydrolysis during food processing, usually by microbial fermentation or proteolytic digestion. Acid hydrolysis, although less expensive is more difficult to control and can result in damage to certain amino acids and is therefore used less frequently.

Production of bioactive peptides via normal digestive processes relies on the active form of the peptide firstly being generated and remaining intact at its site of absorption or action, which can occur throughout the intestine. In many instances this means that the protein or the peptide itself must be at least partially resistant to proteolysis, as normally most food proteins are totally digested during passage through the small intestine. Several proteins such as lactoferrin and immunoglobulins have been shown to partly resist hydrolysis in the small intestine ${ }^{(4,7,8)}$, and tripeptides with the sequence PP at their C-terminus have also been shown to be resistant 
to digestion by peptidases ${ }^{(29,30)}$. Following casein consumption casein phosphopeptides (CPP) have been found in the intestinal contents of rats ${ }^{(31,32)}$ and in rat faeces ${ }^{(33)}$. Casein (native and acid casein) has also been shown to have a role in protecting certain peptides from digestion potentially by blocking the active site of proteolytic enzymes ${ }^{(2)}$.

Due to the different cleavage site specificities of microbial enzymes the peptides produced due to their action are likely to be different to those resulting from cleavage with digestive enzymes such as trypsin. This includes both peptides deriving from the large intestine and also from bacterial fermentation processes such as during cheese ripening. A potential issue with pre-hydrolysed peptides is the risk that active peptides may be hydrolysed by host peptidases during the digestion, absorption processes, although it is also possible that active peptides may be generated from partially hydrolysed and inactive proteins. Issues such as these reinforce the importance of carrying out in vivo studies for demonstrating efficacy, as results from in vitro studies using hydrolysates cannot be extrapolated to imply beneficial effects in vivo.

\section{Absorption of bioactive peptides}

The majority of bioactive peptides described to date cause systemic effects and therefore must either be absorbed from the intestine, act directly on the intestinal tract or via receptors and cell signalling in order to elicit their action. While it is known that the intestine is able to absorb di- and tripeptides relatively easily ${ }^{(34,35)}$ there is little information in the literature documenting the absorption and kinetics of absorption of higher molecular weight bioactive peptides. There is evidence using radioactively labelled peptides suggesting that material infused into the jejunum is rapidly cleared from the systemic circulation $^{(36)}$. However, there is also a report of at least two long peptides derived from casein being detected in the plasma of adults following yoghurt or milk consumption ${ }^{(37)}$. In addition, caseinmacropeptide has been found in the blood of rats after oral administration ${ }^{(38)}$. Although a significant amount of research is still required to document the fate of specific bioactive peptides, it appears that certain food-derived peptides are able to be absorbed, with the extent of absorption determined by the nature of the peptide, and tending to decrease with increasing chain length.

Assuming that the bioactive peptide is absorbed, the concentrations reaching the target cells or receptors must be sufficient to cause a quantifiable and sustained response. Studies in rats have shown that the fermented milk product Calpis ${ }^{\mathrm{TM}}$, which contains the tripeptides VPP and IPP is able to lower blood pressure ${ }^{(39,40)}$, and that these two peptides can be detected in aortal tissue of spontaneously hypertensive rats six hours after the oral administration of a single dose of Calpis $^{\mathrm{TM}}$. In vitro studies using the human intestinal cell-line CaCo-2 have shown that a significant amount of the peptide VPP was transported intact across the monolayer, but was not detected in the cells, leading the authors to conclude that paracellular diffusion was the main mechanism of transport of this peptide across the monolayer ${ }^{(41)}$.

\section{Diverse effects of bioactive proteins and peptides}

The range of physiological effects attributed to the consumption of food-derived bioactive peptides and proteins is diverse including immunomodulatory, anti-hypertensive, anti-carcinogenic, anti-microbial and anti-inflammatory effects amongst others ${ }^{(1,4)}$. Taken at face value, consumption of foods rich in bioactive peptides, particularly those with multiple functions has the potential to have a huge impact on health and wellbeing, being able to optimise health and therefore prevent infection and disease. The ability to prevent and treat chronic disease via consumption of functional foods could vastly decrease health care costs which are expected to rise dramatically in the future given the aging population. However, a major stumbling block is that the veracity of the evidence supporting the effects of different bioactive peptides varies considerably.

\section{Antihypertensive}

Hypertension is a potentially serious condition which increases risk of cardiovascular disease and stroke. Peptides with potential anti-hypertensive effects are among the most extensively studied in the functional foods arena. The majority have been tested for their ability to inhibit the activity of angiotensin-I converting enzyme (ACE), thus lowering the production of the potent vasoconstrictor angiotensin II. Whilst many peptides have been subjected to in vitro studies a number have also been tested in hypertensive animal models and in human subjects. Tripeptides from bonito muscle (IKP) ${ }^{(42)}$ and chicken muscle $(\mathrm{IKW})^{(43)}$ as well as the previously mentioned IPP and VPP from fermented milk ${ }^{(39,40)}$ have all been shown to lower blood pressure in spontaneously hypertensive rats. In a study using spontaneously hypertensive rats the consumption of Calpis ${ }^{\mathrm{TM}}$ led to a reduction in angiotensin-I converting enzyme activity in aortal tissue compared to the control group given saline ${ }^{(40)}$. In an eight week placebo controlled study in hypertensive humans, daily consumption of $100 \mathrm{ml}$ of Calpis ${ }^{\text {TM }}$ was shown to significantly lower blood pressure after both four and eight weeks, compared to the control group in which blood pressure did not change ${ }^{(44)}$. Peptides also exist which have been shown to lower blood pressure in spontaneously hypertensive rats by causing vasodilation mediated via either prostacyclin or the bradykinin B1 receptor ${ }^{(45)}$.

A number of fermented milk drinks, yoghurts and hydrolysed milk preparations which contain either the ACEinhibitory peptides IPP and VPP or VPP, TTMPLW and RY are commercially available in Japan, Spain, USA and Europe $^{(46)}$, with at least seven of these products having Food of Specific Health Use (FOSHU) approval in Japan.

\section{Cholesterol Lowering Bioactive Peptides}

Elevated blood cholesterol has been identified as a major risk factor for cardiovascular disease, and significant research activity is ongoing into methods for the prevention and lowering of plasma cholesterol levels, including the potential use of 
bioactive peptides and proteins. Consumption of a number of food proteins, particularly plant proteins such as soyabean protein, is known to contribute to a lowering of serum cholesterol levels ${ }^{(47)}$. There is a considerable body of evidence from controlled clinical studies showing that replacing animal protein with soya protein results in beneficial effects on serum lipids including a lowering of total cholesterol, low-density lipoprotein (LDL) cholesterol and triglycerides, but not effecting the levels of the so called 'good' cholesterol high-density lipoprotein cholesterol (HDL) ${ }^{(48)}$.

Several mechanisms have been suggested for the cholesterol lowering effects of food proteins, including prevention or blocking of the reabsorption of bile acids and/or cholesterol synthesis ${ }^{(49)}$, inhibition of cholesterol synthesis, and stimulation of LDL receptor (LDL-R) receptor transcription ${ }^{(50)}$. It appears that several or all of these mechanisms may operate based on the proteins or peptides being tested. Following digestion of soyabean protein, high molecular weight core peptides remain, and these are able to prevent the reabsorption of bile acids and therefore are able to lower cholesterol $^{(49)}$. In mice, lower molecular weight peptides such as $\alpha$-lactotensin ( $\beta$-lactoglobulin fragment) and a peptide from soyabean glycinin have both been shown to reduce serum cholesterol levels, although neither increases excretion of faecal cholesterol or bile acids ${ }^{(45)}$. In vitro studies by Cho et al. ${ }^{(50)}$ have shown that the cholesterol lowering activity of a soyabean protein hydrolysate is due at least in part to an upregulation of LDL-R transcription.

\section{Opioid Peptides}

As mentioned a number of reports in the literature describe the effect of opioid peptides on the gastrointestinal tract, where they may have localised effects, effects mediated via gut hormones or systemically-mediated effects following their absorption. Since there are several opioid receptors, each responsible for specific physiological effects, the effects elicited by peptides with opioid activity can be diverse, including affecting appetite, respiratory depression, behaviour (e.g. handling of stress) and gastrointestinal motility. Of the receptors, the $\mu$-receptor affects emotional behaviour, pain sensation and suppression of intestinal motility, the $\delta$-receptor emotional behaviour and the $\kappa$-receptor sedation and the regulation of satiety signals and hence food intake.

The sources of food-derived peptides with opioid activity are diverse, including from cereal ${ }^{(51)}$, bovine-, human-, ovine- and water buffalo-milk ${ }^{(52-55)}$, haemoglobin from bovine blood (haemorphins) ${ }^{(56)}$, gluten and gliaden from wheat, zein from maize, hordein from barley and soya $\alpha$-protein and cytochrome $b^{(57)}$. Generation of opioid peptides can be achieved by digesting the parent protein with a variety of digestive enzymes, either alone or combination: e.g. pepsin, pepsin followed by trypsin, or chymotrypsin alone ${ }^{(58)}$; however to date not all have been shown to be released in the gut following oral administration.

A number of bioactive peptides derived from milk proteins are opioid agonists, binding to opioid receptors and exhibiting morphine-like effects. Peptides in this category include: casomorphins, $\alpha$-lactorphin (from $\alpha$-lactalbumin), $\beta$-lactorphin (from $\beta$-lactoglobulin), serorphin from serum albumin. Other peptides such as lactoferroxins and casoxins are opioid antagonists and are able to depress the agonist activity of enkephalin ${ }^{(59,60)}$. Generally the peptides released from $\alpha$ - and $\beta$-casein elicit agonist responses whilst those from $\kappa$-casein give rise to antagonist responses ${ }^{(61)}$.

\section{Opioid Agonists}

The range of physiological effects attributed to milk-derived opioid agonist peptides are diverse and include inhibiting diarrhoea, prolonging gastrointestinal transit time by inhibiting intestinal peristalsis and motility, modulating amino acid transport, and prolonging analgesia ${ }^{(61,62)}$. The $\beta$-casomorphins were the first identified and are the most studied opioid agonist peptides from food proteins, with $\beta$-casomorphin- $11^{(52,63)}$ and $\beta$-casomorphin- $7^{(64,65)}$ being characterized as in vivo digestion products in both humans and minipigs ${ }^{(61)}$. Casomorphins have also been shown to be produced during cheese ripening due to the proteolytic activity of certain bacteria such as Pseudomonas aeroginosa and Bacillus cereus ${ }^{(66)}$. Studies in rats indicate that $\beta$-casomorphins may have a role in modulating dietary fat intake, with $\beta$-casomorphin 1-7 stimulating intake of a high fat diet, and suppressing intake of a high carbohydrate diet in satiated rats ${ }^{(67)}$. Bovine $\beta$-casomorphins have also been shown to have depressive effects on the central respiratory system, causing a slowing of respiratory frequency and tidal volume in rats and rabbits ${ }^{(68)}$.

In adult humans, absorption of casomorphins has not been observed, therefore it is considered that their effects are limited to the gastrointestinal tract ${ }^{(55)}$. In infants however, there is evidence suggesting that $\beta$-casomorphins can be transported from the blood to both the brain stem $^{(69)}$ and the cardiovascular compartment ${ }^{(55)}$. Passive transport across the intestinal mucosa occurs in neonates and may provide an analgesic effect on the nervous system resulting in calmness and sleep in infants ${ }^{(55)}$. In pregnant/lactating women only (not non-pregnant women) $\beta$-casomorphins or their precursors have been shown to pass through the mammary gland and have been detected in the plasma. Based on this, it has been proposed that $\beta$-casomorphins could potentially modulate the release of prolactin and oxytocin during lactation ${ }^{(61)}$.

The amino acid sequences of the tetrapeptides $\alpha$-lactorphin and $\beta$-lactorphin differ by only one amino acid, yet their physiological effects appear to be quite different. In vitro, $\alpha$-lactorphin exerts a weak inhibitory effect on contractions of guinea pig ileum, while $\beta$-lactorphin causes a non-opioid stimulatory effect ${ }^{(58)}$. Since both $\alpha$-lactorphin and $\beta$-lactorphin are able to displace ${ }^{3} \mathrm{H}$-naloxone from its binding site their actions appear to be elicited via the $\mu$-receptor. Although theoretically the digestion of $1 \mathrm{~L}$ of milk should give rise to sufficient lactorphin concentrations to achieve the effects observed in vitro ${ }^{(58)}$, hydrolysate studies have shown that the yield is actually only $5-14 \%$ of that calculated ${ }^{(58)}$. This, combined with the fact that the generation of $\alpha$-lactorphin and $\beta$-lactorphin during gastrointestinal digestion is yet to be proven raise questions as to whether physiological effects 
due to $\alpha$-lactorphin and $\beta$-lactorphin derived from milk consumption are likely ${ }^{(58)}$.

Enzymatic digestion of wheat gluten has led to the discovery of several opioid peptides which have amino acid sequences quite different to those from other sources ${ }^{(70-71)}$. Studies into the effects of two of these gluten exorphins; A5 and B5 have shown that oral and intravenous administration to rats led to a stimulation of postprandial insulin release ${ }^{(72)}$

Haemorphins have been shown to bind and stimulate opioid receptors in a number of in vitro binding studies ${ }^{(56,73-74)}$. As well as exhibiting agonistic effects, the haemorphins can also act as opioid receptor antagonists ${ }^{(75)}$. Haemorphin-6 and LVV-haemorphin-6 have been shown to have a higher affinity for the $\delta$-binding site than $\beta$-casomorphins and other opioid peptides ${ }^{(73)}$. Haemorphins appear to have analgesic properties similar to classical opioid peptides ${ }^{(76)}$ and may also have a role in the modulation of acute inflammatory responses ${ }^{(77)}$. In addition, hemorphins have been shown to have ACE inhibitory $\operatorname{activity}^{(77,78)}$

However, despite this body of evidence a functional role for the opioid peptides is yet to be demonstrated. One possible role for casomorphins could be to slow the passage of digesta through the gut, thus enabling maximum production of other bioactive peptides and also increasing the time for these peptides to assert their action ${ }^{(79)}$.

\section{Opioid Antagonists}

The number of food-derived opioid antagonists appears to be lower than opioid agonists. The casoxins: A, B, C and D are derived from bovine $\kappa$-casein and/or human $\alpha_{\mathrm{S} 1}$-casein, while lactoferroxins $\mathrm{A}, \mathrm{B}$ and $\mathrm{C}$ are generated from human lactoferrin $^{(61)}$. These antagonists tend to have preferences for the $\mu$ - and $\kappa$-type of opioid receptors ${ }^{(61)}$. There is a significant body of evidence from both animal and human studies ${ }^{(80)}$ demonstrating that ingestion of opioid antagonists leads to appetite regulation and reduced feeding by regulating insulin secretion by the pancreas ${ }^{(81)}$, so these opioid peptides may well have a role in preventing and/or treating obesity.

\section{Osteoprotective proteins and peptides}

Osteoporosis is a chronic, yet largely preventable disease, as bone mineralisation can be improved with sufficient supplies of soluble or available calcium. Milk is a well known source of calcium and in addition contains casein which increases the absorption of calcium in the intestine and is therefore osteoprotective. Caseinophosphopeptides (CPP), formed during the digestion of casein in the gastrointestinal tract, are also able to chelate calcium, and since this complex remains soluble there is the potential for enhanced calcium absorption across enterocytes in the distal intestine. CPP carries a large number of negative charges due to a high acidic amino acid content, and this renders the peptides resistant to further proteolysis, and perhaps explains why CPP have been detected in the intestinal contents of animals fed intact casein and purified $\beta$ - casein $^{(32,33,52,82,83)}$.
Results from both animal and human studies investigating the effects of casein based diets on calcium absorption have shown conflicting results. Yuan et al. ${ }^{(84)}$ showed that calcium solubility, absorption and hence bioavailability was enhanced in animals fed casein based diets compared to soya based diets, however a long term study in mini-pigs only showed beneficial effects from consumption of CPP under specific conditions such as vitamin D deficiency ${ }^{(85)}$. Results from a trial in humans where CPP was incorporated into a rice-based infant food led to an increase in both calcium and zinc absorption, although subsequent incorporation into a whole grain infant cereal did not achieve the same result, possibly indicating matrix effects ${ }^{(86)}$. In a trial in post-menopausal women Narva et $a l .{ }^{(87)}$ showed there was no effect of CPP-enriched milk on several calcium and calcium related parameters.

Whey components have also been shown to have beneficial effects on bone metabolism. A fraction from whey known as milk basic protein or MBP has been shown to promote bone formation and inhibit bone resorption in both in vitro and in vivo studies. Two double-blind, placebo-controlled human studies:one carried out in 35 healthy young women average age 21.3 years $^{(88)}$ and one completed in 27 healthy menopausal women average age of 50.5 years ${ }^{(89)}$ both showed that MBP supplementation ( $40 \mathrm{mg} /$ day) for a period of 6 months led to increased bone mineral density compared to the control group. Changes in the concentrations of biochemical indices of bone metabolism over these study periods, namely an increase in the bone formation marker serum osteocalcin in the younger women ${ }^{(88)}$ and decrease in the bone resorption marker urinary cross-linked N-teleopeptides of type-I collagen in both studies suggest the MBP is acting by enhancing bone formation and reducing bone resorption ${ }^{(88,89)}$. In vitro studies indicate that MBP may have a direct effect on osteoclasts thus suppressing bone resorption ${ }^{(90)}$.

\section{The potential use of bioactivity as an additional measure of protein quality: Issues to be considered}

If the physiological effects elicited by the consumption of foods containing bioactive proteins and peptides are to be considered as a factor contributing to dietary protein quality then it is imperative that measurable health benefits are demonstrated, and these must be able to be quantitated in a standardised manner. Standardised methods will also be needed to determine adequate doses of the bioactive protein or peptide, the amounts of the bioactive in the food product and the safety of the product. Methods will also be needed to show that the bioactive peptide or protein can be detected in the tissue being affected, and at levels capable of eliciting a biological effect. These factors are also those likely to be required by regulatory authorities concerned both with food safety and granting permission for marketing with recognised health claims.

\section{Demonstration of measurable health effects}

One problem relating to the demonstration of measurable health effects is that many of the studies describing beneficial 
effects have been performed in vitro. It is therefore important that in vivo trials are conducted to assess true efficacy. In fact it has been suggested that in many instances an in vitro approach to testing is not valuable at all, one reason being that bioavailability issues due to several factors including low absorption and rates of metabolism are not accounted for ${ }^{(91)}$. Another issue with in vitro testing was highlighted by Fujita et al. ${ }^{(92)}$ when they demonstrated that some peptides reported to have ACE inhibitory activity were acting by competing with the assay's synthetic substrate rather than actually inhibiting the enzyme. Cost and ethical issues are among the reasons for carrying out in vitro studies to screen for potential bioactive peptides, however, given that the peptides actually generated by digestion may be different to those being tested in vitro it is possible that bioactive peptides might also be missed using this approach.

Another issue relating to the demonstration of measurable health benefits is that while for some effects such as cholesterol lowering and blood-pressure lowering the measures and methods are clear, this is potentially a major issue in other areas of bioactive research e.g. immunomodulatory proteins and peptides. For whilst there is a significant amount of literature $^{(93)}$ on the immunomodulatory effects of foodderived bioactive peptides there is considerable debate as to whether the changes in parameters such as lymphocyte proliferation, phagocytosis and natural killer cell activity observed with in vitro and ex vivo studies will in fact lead to a health benefit such as resistance to disease or infection. Some studies have demonstrated the ability of certain peptides and proteins to enhance antibody production against vaccines. However, to date there are only limited numbers of studies showing antiinfection properties of certain bioactive peptides and proteins. It has also been argued that stimulation of the immune system could actually be deleterious leading to chronic inflammation and other undesired effects. Thus the effects of bioactive peptides in terms of a measureable outcome relating to health remains unclear, which would make assessing their contribution to dietary protein quality by optimising health difficult at the current time.

\section{Dose response and safety}

With bioactive peptides being derived from foods there is the potential misconception that by extrapolation their consumption is safe. While this may well be the case if products are consumed at normal levels, there is no guarantee that the increased consumption that is highly likely to occur if the consumer believes there to be a significant health benefit, will not result in levels beyond a safe limit, which could result in deleterious effects. Trials should be performed to show the dose response and safety of long term ingestion particularly in relation to areas such as allergenicity, toxicity and mutagenicity, especially if health related claims are to be made. Ideally animal studies should be followed by trials in humans including intervention studies where appropriate.

Standardised methods are required to accurately quantify and characterise bioactive peptides from all sources, be they of plant or animal origin ${ }^{(46)}$. These methods must be sensitive enough to allow detection in vivo at a relevant target site. For example if the peptide acts systemically then it must be detectable in human blood in its biologically active form in quantities sufficient to elicit a measurable response. Since mechanisms of action may differ from one peptide to another the half-life of the peptide in the blood must also be measured as a guide to both efficacy and safety. Clearly peptides with long half-lives consumed frequently could potentially run the risk of exceeding safe upper limits, while those with very short half-lives may be degraded before they can cause a response.

\section{Methods for quantifying and characterising bioactive peptides}

Potential methods for identifying food-derived peptides in blood and other biological samples as well as in food matrices are being developed. The complexity of protein hydrolysates, which can contain hundreds of peptide sequences, of which the bioactive peptide may represent only a minor constituent, combined with the complex nature of food matrices has meant that the task of identifying, characterising and quantifying food-derived bioactive peptides has been a difficult and often labour-intensive one. The advent of soft ionization mass spectrometry (MS) techniques such as fast atom bombardment (FAB), electrospray ionisation (ESI) and matrixassisted laser desorption ionisation (MALDI) has heralded a new era for protein characterisation. MS techniques are highly selective and sensitive, with the result that they have been successfully used to not only identify and characterise, but also when combined with other techniques such as HPLC (i.e. LC/MS or LC/MS/MS), to quantify food-derived bioactive peptides in both foods and biological fluids ${ }^{(94)}$. There are however, several potential problems inherent with MS techniques such as repeatability and matrix effects which result in suppression of ionisation, and although these can usually be overcome by the inclusion of an internal standard other methods such as ELISA or RIA are frequently used for quantitation purposes.

Since an adequate dosage of bioactive peptides is essential in order to elicit a measureable biological effect it has become important for product manufacturers to be able to accurately quantify the levels of the active peptide(s) in the final product. Various techniques for quantifying ACE-inhibitory peptides in functional foods have been described by a number of authors with detection limits as low as $0.01 \mathrm{ng} / \mathrm{ml}^{(94)}$. Methods for detecting lactoferricin in biological fluids and wheat glutenderived opioid peptides in cerebrospinal fluid are amongst others that have also been published ${ }^{(94)}$.

Other techniques for isolating, characterising and quantifying bioactive peptides include solid-phase extraction, followed by size-exclusion chromatography and reversed-phase HPLC. The successful identification and quantitation of foodderived peptides from a fish gelatine hydrolysate has been described using the method above ${ }^{(95)}$. In this particular example two volunteers consumed $20 \mathrm{~g}$ of the hydrolysate and collagen peptides were detected in the plasma $60 \mathrm{~min}$ later. Interestingly, both the quantity and the structure of the 
identified peptides differed between the individuals suggesting that the digestive and/or absorption processes differed. This finding reinforces the importance of identifying the amino acid sequences of bioactive peptides and determining optimum levels for eliciting beneficial effects and the upper levels for safety, as clearly depending on each individuals' metabolism, the concentration of bioactive peptides found in the blood may vary markedly from one individual to another.

\section{Conclusions}

The area of food bioactive proteins and peptides is a rapidly growing field of study and no doubt more bioactive peptides and proteins along with additional physiological effects will be discovered in the future. A number of factors can potentially impact on the ability of a bioactive peptide or protein to elicit an effect. The amounts of bioactive peptides generated must be sufficient to elicit a response, but should not be so high as to be unsafe, thus causing negative effects. To do this, methods must be developed and standardised that enable not only the measurement of health benefits but also of the level of bioactive peptides which are absorbed into the bloodstream. Once standardised, such methods may provide a new perspective and an additional mechanism for describing dietary protein quality which is currently not encompassed by the use of measures such as protein digestibility-corrected amino acid score (PDCAAS). This would take the measure of protein quality beyond one of nitrogen balance and more towards optimum health, encompassing the specific physiological roles of bioactive proteins and peptides as well the key regulatory roles of certain amino acids. In addition such information gained using standardised techniques will prove invaluable to regulatory authorities and should aid in the development of regulations and policy regarding acceptable scientific validation of efficacy and safety claims ${ }^{(46)}$.

\section{Acknowledgements}

The author has no conflict of interest to declare. K.R.M wrote the paper and has sole responsibility for the content. This research received no specific grant from any funding agency in the public, commercial or not-for-profit sectors.

\section{References}

1. Korhonen H (2009) Milk-derived bioactive peptides: From science to applications. J Funct Foods 1, 177-187.

2. Kelly D \& Coutts APG (1997) Biologically active peptides in colostrum and milk. In Digestive Physiology in Pigs, pp. 163-170 [J-P Laplace, C Février and A Barbeau, editors]. Saint Malo, France: INRA.

3. Meisel H (2005) Biochemical properties of peptides encrypted in bovine milk proteins. Curr Med Chem 12, 1905-1919.

4. Moller NP, Scholz-Ahrens KE, Roos N, et al. (2008) Bioactive peptides and proteins from foods: indication for health effects. Eur J Nutr 47, 171-182.
5. Hu WL, Mazurier J, Sawatzki G, et al. (1988) Lactotransferrin receptor of mouse small-intestinal brush border. Biochem J 249, 435-441.

6. Guesdon B, Pichon L \& Tomé D (2006) Opioid Peptides. In Nutraceutical Proteins and Peptides in Health and Disease, pp. 367-376 [Y Mine and F Schahidi, editors]. Boca Raton, Florida: CRC Press.

7. Drescher K, Roos N, Pfeuffer M, et al. (1999) Recovery of ${ }^{15} \mathrm{~N}$-Lactoferrin is higher than that of ${ }^{15} \mathrm{~N}$-Casein in the small intestine of suckling, but not adult miniature pigs. J Nutr 129, 1026-1030.

8. Roos N, Mahe S, Benamouzig R, et al. (1995) ${ }^{15} \mathrm{~N}$-labeled immunoglobulins from bovine colostrum are partially resistant to digestion in human intestine. $J$ Nutr $\mathbf{1 2 5}$, $11238-11244$.

9. Korhonen H \& Marnila P (2006) Bovine milk antibodies for protection against microbial human disease. In Nutraceutical Proteins and Peptides in Health and Disease, pp. 137-159 [Y Mine and F Shahidi, editors]. Boca Raton, Florida: CRC Press.

10. Korhonen H \& Pihlanto A (2007) Technological options for the production of health-promoting proteins and peptides derived from milk and colostrum. Curr Pharm Des $\mathbf{1 3}$ $829-843$.

11. Baker EN, Baker HM, Koon N, et al. (2002) Lactoferrin: bioactive properties and applications. Bull Int Dairy Fed 375 , $54-58$.

12. Baveye S, Elass E, Mazurier J, et al. (1999) Lactoferrin: a multifunctional glycoprotein involved in the modulation of the inflammatory process. Clin Chem Lab Med 37, 281-286.

13. Elass E, Baveye S, Fernig D, et al. (2002) Lactoferrin interacts with CD14s and inhibits the expression of endothelial adhesion molecules, induced by the CD14s-lipopolysaccharide complex. Biochem Cell Biol 80, 165.

14. Britton JR, George-Nasscimento C \& Koldovsky O (1988) Luminal hydrolysis of recombinant human epidermal growth factor in the rat gastrointestinal tract: segmental and developmental differences. Life Sci 43, 1339-1347.

15. Britton JR, George-Nasscimento C, Udall JN, et al. (1989) Minimal hydrolysis of epidermal growth factor by gastric fluid of preterm infants. Gut 30, 327-332.

16. Read LC, Gale SM \& George-Nascimento C (1987) Intestinal absorption of epidermal growth factor in newborn lambs. In Human Lactation 3 The effects of human milk on the recipient infant, pp. 199-204 [AS Goldman, SA Atkinson and LA Hansen, editors]. New York: Plenum Press.

17. Schusdziarra V, Schick A, De La Fuente A, et al. (1983) Effect of $\beta$-casomorphins and analogs on insulin release in dogs. Endocrinology 112, 885-889.

18. Weaver LT (1997) Significance of bioactive substances in milk to the human neonate. Livestock Prod Sci 50, 139-146.

19. Donnet-Hughes A, Duc N, Serrant P, et al. (2000) Bioactive molecules in milk and their role in health and disease: The role of transforming growth factor- $\beta$. Immunol Cell Biol 78, 74-79.

20. Beattie RM, Schiffrin EJ, Donnet-Hughes A, et al. (1994) Polymeric nutrition as the primary therapy in children with small bowel Crohn's disease. Aliment Pharmacol Ther 8, 609-615.

21. Fell JM, Paintin M, Arnaud-Battandier F, et al. (2000) Mucosal healing and a fall in mucosal pro-inflammatory cytokine mRNA induced by a specific oral polymeric diet in paediatric Crohn's disease. Aliment Pharmacol Ther 14, 281-289.

22. Ozawa T, Miyata M, Nishimura M, et al. (2009) Transforming growth factor- $\beta$ activity in commercially available pasteurized cow milk provides protection against inflammation in mice. J Nutr 139, 69-75. 
23. Schriffin E, El Yousfi M, Faure M, et al. (2005) Milk caseinbased diet containing TGF- $\beta$ controls the inflammatory reaction in the HLA-B27 transgenic rat model. J Parent Enteral Nutr 29, S141-S148.

24. Neurath MF, Fuss I, Kelsall BL, et al. (1996) Experimental granulomatous colitis in mice is abrogated by induction of TGF-beta-mediated oral tolerance. $J$ Exp Med 183, 2605-2616.

25. Sanchez de Medina F, Daddaoua A, Requena P, et al. (2010) New insights into the immunological effects of food bioactive peptides in animal models of intestinal inflammation. Proc Nutr Soc 69, 454-462.

26. Pellegrini A (2003) Antimicrobial peptides from food proteins. Curr Pharma Design 9, 1225-1238.

27. Teschemacher H (2003) Opioid receptor ligands derived from food proteins. Curr Pharma Design 9, 1331-1344.

28. Moughan PJ, Fuller MF, Han K-S, et al. (2007) Food-derived bioactive peptides influence gut function. Int J Sport Nutr Exerc Metab 17, S5-S22.

29. Yoshimoto R, Fischl M, Orlowski RC, et al. (1978) Postproline cleaving enzyme and post-proline dipeptidyl amino-peptidase comparison of two peptidases with high specificity for proline residues. J Biol Chem 253, 3708-3716.

30. Mock LW, Green PC \& Boyer KD (1990) Specificity and pH dependence for acylproline cleavage by prolidase. $J$ Biol Chem 265, 19600-19605.

31. Naito H \& Suzuki H (1974) Further evidence for the formation in vivo of phosphopeptide in the intestinal lumen from dietary $\beta$-casein. Agr Biol Chem 38, 1543-1545.

32. Kitts DD, Yuan YV, Nagasawa T, et al. (1992) Effect of casein, casein phosphopeptides and calcium intake on ileal ${ }^{45} \mathrm{Ca}$ disappearance and temporal systolic blood pressure in spontaneously hypertensive rats. Br J Nutr 68, 765-781.

33. Kasai T, Honda T \& Kiriyama S (1992) Caseinphosphopeptides (CPP) in feces of rats fed casein diet. Biosci Biotech Biochem 56, 1150-1151.

34. Adibi SA \& Morse EL (1971) Intestinal transport of dipeptides in man: relative importance of hydrolysis and intact absorption. J Clin Invest 50, 2266-2275.

35. Hara H, Funabiki R, Iwata M, et al. (1984) Portal absorption of small peptides in rats under unrestrained conditions. J Nutr 114, 1122-1129.

36. Bloch KJ, Wright JA, Bishara SM, et al. (1988) Uptake of polypeptide fragments of proteins by rat intestine in vitro and in vivo. Gastroenterology 95, 1272-1278.

37. Chabance B, Marteau P, Rambaud JC, et al. (1998) Casein peptide release and passage to the blood in humans during digestion of milk or yogurt. Biochimie 80, 155-165.

38. Fosset S, Fromentin G, Gietzen DW, et al. (2002) Peptide fragments released from Phe-caseinmacropeptide in vivo in the rat. Peptides 23, 1773-1781.

39. Nakamura Y, Masuda O \& Takano T (1996) Decrease of tissue angiotensin I-converting enzyme activity upon feeding sour milk to spontaneously hypertensive rats. Biosci Biotech Biochem 60, 488-489.

40. Masuda O, Nakamura Y \& Takano T (1996) Antihypertensive Peptides Are Present in Aorta after Oral Administration of Sour Milk Containing These Peptides to Spontaneously Hypertensive Rats. J Nutr 126, 3063-3068.

41. Satake M, Enjoh M, Nakamura Y, et al. (2002) Transepithelial Transport of the Bioactive Tripeptide, Val-Pro-Pro, in Human Intestinal Caco-2 Cell Monolayers. Biosci Biotechnol Biochem 66, 378-384.

42. Yokoyama K, Chiba H \& Yoshikawa M (1992) Peptide inhibitors for angiotensin I-converting enzyme from thermolysin digest of dried bonito. Biosci Biotech Biochem 56, 1541-1545.

43. Fujita H, Yokoyam K \& Yoshikawa M (2000) Classification and antihypertensive activity of angiotensin I-converting enzyme inhibitory peptides derived from food proteins. J Food Sci 65, 564-569.

44. Hata Y, Yamamoto M, Ohni M, et al. (1996) A placebocontrolled study of the effect of sour milk on blood pressure in hypertensive subjects. Am J Clin Nutr 64, 767-771.

45. Yoshikawa M, Fujita H, Matoba N, et al. (2000) Bioactive peptides derived from food proteins preventing lifestylerelated diseases. Biofactors 12, 143-146.

46. Gilani GS, Xiao C \& Lee N (2008) Need for accurate and standardized determination of amino acids and bioactive peptides for evaluating protein quality and potential health effects of foods and dietary supplements. JOAC Int 91, 894-900.

47. Carroll KK (1978) The role of dietary protein in hypercholesterolemia and atherosclerosis. Lipids 13, 360-365.

48. Anderson JW, Johnstone BM \& Cook-Newell ME (1995) Meta-Analysis of the Effects of Soy Protein Intake on Serum Lipids. $N$ Eng J Med 333, 276-282.

49. Sugano M, Yamada Y, Yoshihida K, et al. (1988) The hypocholesterolemic action of the undigested fraction of soybean protein in rats. Atherosclerosis 72, 115-122.

50. Cho S-J, Juillerat MA \& Lee C-H (2007) Cholesterol lowering mechanism of soybean protein hydrolysate. J Agric Food Chem 55, 10599-10604.

51. Morley JE, Levine AS, Yamada T, et al. (1983) Effect of exorphins on gastrointestinal function, hormonal release and appetite. Gastroenterology 84, 1517-1523.

52. Meisel H \& Frister H (1989) Chemical characterization of bioactive peptides from in vivo digests of casein. J Dairy Res $\mathbf{5 6}$, 343-349.

53. Brantl V, Teschemacher H, Henschen A, et al. (1979) Novel opioid peptides derived from casein (beta-casomorphins). II. Structure of active components from bovine casein peptone. Hoppe-Seyler's Z Physiol Chem 360, 1211-1216.

54. Brantl V (1984) Novel opioid peptides derived from human beta-casein: human beta-casomorphins. Eur J Pharmacol 106, 213-214.

55. Teschemacher H, Koch G \& Brantl V (1997) Milk proteinderived opioid receptor ligands. Biopoly 43, 99-117.

56. Brantl V, Gramsch C, Lottspeich F, et al. (1986) Novel opioid peptides derived from hemoglobin: hemorphins. Eur J Pharmacol 125, 309-310.

57. Meisel H \& Schlimme E (1990) Milk proteins: precursors of bioactive peptides. Trends Food Sci Technol 1, 41-43.

58. Pihlanto-Leppälä A (2001) Bioactive peptides derived from bovine whey proteins: opioid and ace-inhibitory peptides. Trends Food Sci Technol 11, 347-356.

59. Yoshikawa M, Tani F, Yoshimura T, et al. (1986) Opioid Peptides from Milk Proteins. Agric Biol Chem 50, 2419-2421.

60. Yoshikawa M, Tani F \& Chiba H (1988) Structure-activity relationship of opioid antagonist peptides derived from milk proteins. In Peptide Chemistry, pp. 473-476 [T Shiba, editor]. Osaka: Protein Research Foundation.

61. Clare DA \& Swaisgood HE (2000) Bioactive milk peptides: A prospectus. J Dairy Sci 83, 1187-1195.

62. Meisel H (1998) Overview on milk protein-derived peptides. Int Dairy J 8, 363-373.

63. Meisel H (1986) Chemical characterization and opioid activity of an exorphin isolated from in vivo digests of casein. FEBS Lett 196, 223-227.

64. Svedberg J, de Haas J, Leimenstoll G, et al. (1985) Demonstration of $\beta$-casomorphin immunoreactive materials in 
in vitro digests of bovine milk and in small intestine contents after bovine milk ingestion in adult humans. Peptides $\mathbf{6}$, $825-830$.

65. Singh M, Rosen CL, Chang KJ, et al. (1989) Plasma [beta]casomorphin-7 immunoreactive peptide increases after milk intake in newborn but not in adult dogs. Pediatr Res 26, 34-38.

66. Hamel V, Kielwein G \& Teschemacher H (1985) $\beta$-Casomorphin immunoreactive materials in cows' milk incubated with various bacterial species. J Dairy Res 52, 139-148.

67. Lin L, Umahara M, York DA, et al. (1998) $\beta$-Casomorphins stimulate and enterostatin inhibits the intake of dietary fat in rats. Peptides 19, 325-331.

68. Hedner J \& Hedner T (1987) $\beta$-casomorphins induce apnea and irregular breathing in adult rats and newborn rabbits. Life Sci 41, 2303-2312.

69. Pasi A, Mahler H, Lansel N, et al. (1993) Res Commun Chem Pathol Pharmacol 80, 305-322.

70. Fukudome S-I \& Yoshikawa M (1992) Opioid peptides derived from wheat gluten: Their isolation and characterization. FEBS Lett 296, 107-111.

71. Fukudome S-I \& Yoshikawa M (1993) Gluten exorphin C: A novel opioid peptide derived from wheat gluten. FEBS Lett 316, 17-19.

72. Fukudome S-I, Shimatsu A, Suganuma H, et al. (1995) Effect of gluten exorphins a5 and b5 on the postprandial plasma insulin level in conscious rats. Life Sci 57, 729-734.

73. Glämsta E-L, Marklund A, Hellman U, et al. (1991) Isolation and characterization of a hemoglobin-derived opioid peptide from the human pituitary gland. Regul Pept 34, 169-179.

74. Piot J-M, Zhao Q, Guillochon D, et al. (1992) Isolation and characterization of two opioid peptides from a bovine hemoglobin peptic hydrolysate. Biochem Biophys Res Commun 189, 101-110.

75. Zadina JE, Kastin AJ, Kersh D, et al. (1992) Tyr-MIF-1 and hemorphin can act as opiate agonists as well as antagonists in the guinea pig ileum. Life Sci 51, 869-885.

76. Davis TP, Gillespie TJ \& Porreca F (1989) Peptide fragments derived from the $\beta$-chain of hemoglobin (hemorphins) are centrally active in vivo. Peptides 10, 747-751.

77. Nyberg F, Sanderson K \& Glämsta E-L (1997) The hemorphins: a new class of opioid peptides derived from the blood protein hemoglobin. Biopoly 43, 147-156.

78. Ivanov VT, Karelin AA, Philippova MM, et al. (1997) Hemoglobin as a source of endogenous bioactive peptides: the concept of tissue-specific peptide pool. Biopoly 43, 171-188.

79. Schanbacher FL, Talhouk RS, Murray FA, et al. (1998) MilkBorne Bioactive Peptides. Int Dairy J 8, 393-403.

80. Shahidi F \& Zhong Y (2008) Bioactive peptides. JOAC Int 91 , 914-931.

81. Kitts DD (1994) Bioactive substances in food: identification and potential uses. Can J Physiol Pharmacol 72, 423-434.
82. Naito H, Kawakami A \& Inamura T (1972) In vivo formation of phosphopeptide with calcium-binding property in the small intestinal tract of the rat fed on casein. Agric Biol Chem 36, 409-415.

83. Sato R, Noguchi $T$ \& Naito H (1983) The necessity for the phosphate portion of casein molecules to enhance Ca absorption from the small intestine. Agric Biol Chem 47, 2415-2417.

84. Yuan YV \& Kitts DD (1991) Confirmation of calcium absorption and femoral utilization in spontaneously hypertensive rats fed casein phosphopeptide supplemented diets. Nutr Res 11, 1257-1272.

85. Scholz-Ahrens KE, de Vrese M \& Barth CA (1991) Influence of casein-derived phosphopeptides on the bioavailability of calcium in vitamin D-deficient miniature pigs. In Gene regulation, structure-function analysis and clinical application, pp. 724-725 [AW Norman, R Bouillon and M Thomasset, editors]. Berlin: W de Gruyter.

86. Hansen M, Sandstöm B, Jensen M, et al. (1997) Casein phosphopeptides improve zinc and calcium absorption from rice-based but not from whole-grain infant cereal. J Pediatr Gastroenterol Nutr 24, 56-62.

87. Narva M, Karkkainen M, Poussa T, et al. (2003) Caseinphosphopeptides in milk and fermented milk do not affect calcium metabolism acutely in postmenopausal women. $J$ Am Coll Nutr 22, 88-93.

88. Uenishi K, Ishida H, Toba Y, et al. (2007) Milk basic protein increases bone mineral density and improves bone metabolism in healthy young women. Osteoporos Int 18, 385-390.

89. Aoe S, Koyama T, Toba Y, et al. (2005) A controlled trial of the effect of milk basic protein (MBP) supplementation on bone metabolism in healthy menopausal women. Osteoporos Int 16, 2123-2128.

90. Toba Y, Takada Y, Yamamura J, et al. (2000) Milk basic protein: a novel protective function of milk against osteoporosis. Bone 27, 403-408.

91. Foltz M, van der Pijl PC \& Duchateau GSMJE (2010) Current in vitro testing of bioactive peptides is not valuable. J Nutr 140, 117-118

92. Fujita H, Yokoyama K \& Yoshikawa M (2000) Classification and antihypertensive activity of angiotensin I-converting enzyme inhibitory peptides derived from food proteins. J Food Sci 65, 564-569.

93. Rutherfurd-Markwick KJ \& Moughan PJ (2005) Bioactive peptides derived from food. JOAC Int $\mathbf{8 8}, 955-966$.

94. Del Mar Contreras M, Lopez-Exposito I, HernandezLedesma B, et al. (2008) Application of mass spectrometry to the characterization and quantification of food-derived bioactive peptides. JOAC Int 91, 981-994.

95. Sato K, Iwai K \& Aito-Inoue M (2008) Identification of foodderived bioactive peptides in blood and other biological samples. JOAC Int 91, 995-1001. 